\title{
SCREENING SUGARCANE SOMACLONES AND THEIR PARENT VARIETIES AGAINST RED ROT (Colletotrichum falcatum) AND ASSESSMENT OF VARIABILITY BY RAPD AND SSR MARKERS
}

\author{
Kuasha Mahmud $^{1 *}$, K. M. Nasiruddin², M. A Hossain ${ }^{3}$ and L. Hassan ${ }^{4}$ \\ Department of Biotechnology, Bangladesh Agricultural University, Mymensingh-2202
}

\begin{abstract}
The experiment was conducted to find out red rot disease causing pathogenic reactions of somaclones $\left(R_{0}\right)$ and their respective parents at BSRI farm in the cropping season 2011-2012. A total number of sugarcane genotypes 24 including 4 sugarcane varieties viz. Isd 37 , Isd 38 , Isd 39 and also Isd 40 were inoculated to screen red rot resistant levels $(R=$ Resistant, $M R=$ Moderately Resistant) to susceptible levels $(\mathrm{S}=$ Susceptible, $\mathrm{MS}=$ Moderately Susceptible, $\mathrm{HS}=$ Highly Susceptible) after 7 months of planting. As a result, Isd 37 variety (source/parent) and its somaclones CC-37-12 and CC-37-86 were found to be resistant while 7 somaclones showed moderately resistant reaction. Furthermore, somaclones of Isd 38 variety viz. CC-38-2 as moderately resistant, CC-38-10 as moderately susceptible and also CC-11(38)-8 as susceptible reaction were recorded while Isd 38 variety showed resistant reaction. On the other hand, Isd 39 and Isd 40 source varieties with their somaclones were found as resistant reaction against red rot pathogen. Some somaclones showed different reaction from their source varieties such as moderately resistant somaclones were obtained from resistant source variety Isd 37 while somaclones CC-38-2 as moderately resistant, CC-38-10 as moderately susceptible and somaclone CC-38-8 as susceptible were obtained from resistant source variety Isd 38 against red rot pathogens respectively. Besides, some somaclones showed similar reaction from their resistant source varieties Isd 37, Isd 39 and also Isd 40. It revealed that reaction against red rot pathogen, induced somaclones showed variation with their source varieties. Red rot resistance somaclones were isolated and assessed for
\end{abstract}

\footnotetext{
* Corresponding author email: mahmudkuasha@gmail.com

${ }^{1}$ PSO, Biotechnology Division, Bangladesh Sugarcrop Research Institute, Ishurdi, Pabna

${ }^{2}$ Prof. Dept. of Biotechnology, Bangladesh Agricultural University, Mymensingh

${ }^{3}$ CSO, Biotechnology Division, Bangladesh Sugarcrop Research Institute, Ishurdi, Pabna

${ }^{4}$ Prof. Dept. of Genetics \& Plant Breeding, Bangladesh Agricultural University, Mymensingh
} 
the presence of variability through RAPD and SSR markers. Cluster and sub cluster formation verified the presence of variability in the red rot resistance somaclones with respect to the parent.

Keywords: Fungus, inoculation, red rot disease, resistant, sugarcane and susceptible

\section{INTRODUCTION}

Worldwide, Sugarcane (Saccharum officinarum L) is a major source of commercial sugar along with many other value added products and by-product. Red rot is the most destructive disease of sugarcane in Bangladesh. The genus Saccharum contains three cultivated (Saccharum officinarum, Saccharum sinensis and Saccharum barbari) and two wild (Saccharum robustum and Saccharum spontanium) species (Kochhar, 1998). Somaclonal variation has been used by various scientists to recover improved plantlets from a number of genotypes. Somaclones may show variation for different parameters like yield, sugar recovery, disease resistance, maturity, drought and salt tolerance. It is not controversial that tissue culture techniques are playing their part in sugarcane improvement and at the same time for a plant breeder assessment of genetic diversity, they are very essential in tissue culture derived plants. Production of disease-free large number seedlings during the planting season is laborious and time consuming. Development of more efficient methods for large-scale production of pathogen free planting material would contribute significantly to the overall productivity of the sugar industry. Tissue culture offers an opportunity to mass produce disease free planting material and is now used to supplement commercial sugarcane propagation in many countries including Brazil, the United States, India and Cuba (Lakshmanan et al., 2006). Red rot (Colletotrichum falcatum Went.) disease is the most dreadful disease of Bangladesh. It causes the greatest loss to sugarcane industry. Moreover, most of the newly released cultivars to replace the susceptible ones succumb to the pathogen almost as soon as they become popular due to the frequent emergence of new variants of the pathogen. Management of the disease by the use of disease-free seed canes for planting is impractical due to the difficulty in diagnosing the dormant infections of the fungus in seed canes under field conditions (Viswanathan \& Samiyappan, 2002). Modern sugarcane cultivars are known to have one of the most complex genomes. Since, most traits in sugarcane are multigenic and/or multi-allelic and are quantitatively inherited, they thus represent a particular challenge for breeding, genetics and gene cloning purposes (Butterfield et al., 2001). Considerable progress has been made in the mapping of the sugarcane genome and its progenitors (Aitken et al., 2005). Somaclones and their sources varieties were screened for their reaction to isolates of red rot pathogen to get resistant genotypes. Therefore, screening of sugarcane genotypes against red rot pathogen is a pre-requisite in the varietal improvement. Hence, this experiment was conducted to find out the level of 
resistance of induced somaclones and their sources varieties against red rot pathogen (Colletotrichum falcatum Went.).

\section{MATERIAS AND METHODS}

The leaf sheath explants were collected from 8-10 months old field grown sugarcane from Bangladesh Sugarcrop Research Institute (BSRI) experimental field at Ishurdi, Pabna. At first MS medium supplemented with green coconut water (10\%) containing $3 \mathrm{mg} \mathrm{l}^{-1}$ of 2, 4-D was prepared for callus induction. After five weeks of explantation, the calli were inoculated for shooting on MS medium supplemented with concentration BAP $\left(2 \mathrm{mg} \mathrm{l}^{-1}\right)+$ Kinetin $\left(1 \mathrm{mg} \mathrm{l}^{-1}\right)$ and maintained by subculturing every two weeks and then regenerated shoots were inoculated for rooting by sub-culturing every two weeks on MS medium supplemented with $5 \mathrm{mg} \mathrm{l}^{-1}$ NAA. Callus culture derived somaclones $\left(\mathrm{R}_{0}\right)$ and their parent varieties were planted at BSRI Biotechnological experimental field on February, 2011. Isolates of Colletortichum falcatum of different cane growing zones were used for inoculation. The pathogen was collected from different zones and maintained in the oat meal slant. Artificial inoculation with different isolates was done on 7-8 months old induced somaclones along with sources varieties. Eight to ten days old sporulating cultures of the fungus were used for inoculation. Inoculation was made with individual as well as with mixed isolates of Colletotrichum falcatum. Ten healthy canes of each somaclone and their sources varieties were inoculated by spore suspension (spore conc. $10^{6} \mathrm{ml}^{-1}$ ) of red rot disease causing fungus (colletotrichum falcatum) with the help of hypodermic syringe method. After two months of inoculation, data on disease development in the canes were recorded. On the basis of disease index (Table 2) the somaclones and their parents were categorized (Table 1) as Resistant (R), Moderately Resistant (MR), Moderately Susceptible (MS), Susceptible (S) and Highly Susceptible (HS) to this disease. Red rot inoculation result sheets (Appendix VI) were used for screening somaclones and their parents as Resistant (R), Moderately Resistant (MR), Moderately Susceptible (MS), Susceptible (S) and Highly Susceptible (HS) to red rot disease. For molecular studies, young meristem cylinder from 2 somaclones and their donor parents were taken from $\mathrm{R}_{0}$ regeneration and grinded using extraction buffer solution and amount of chemicals were important considerations for DNA isolation. DNA was extracted from sugarcane using the method modified and combined from the methods of Aljanabi et al. (1999) and mini-prep method adopted from Hossain et al. (2006) and Shahnawaz (2006). The DNA concentration was determined by Nano drop Spectrophotometer (2000/2000c, Thermo Scientific, USA) and was diluted to a concentration of $50 \mathrm{ng}$ $\mu 1^{-1}$. Samples were stored at $-20^{0} \mathrm{C}$ for further use. Polymorphism was studied using Random Amplified Polymorphic DNA (RAPD) as illustrated by Mondal et al. (2009) which supported by Williams et al. (1990). Six RAPD and nine SSR primers (Operon Technologies, Inc., Alameda, California, USA) were used. The reaction mixtures 10 $\mu 1$ was amplified for each DNA sample in a Thermal Cycler (Genius, Techne, 
Cambridge Limited). Agarose gel (1.4\% and 2\%, w/v) were used for RAPD and SSR electrophoresis. The Ethidium Bromide at $10 \mathrm{mg} \mathrm{ml}^{-1}$ was added in gel for detection. Bands were viewed under ultraviolet trans-illuminator and documentation (FluorChem FC2, Cell Biosciences, USA). The presence and absence of a DNA fragment was considered as basis of polymorphism. DNA loci if present were scored as ' 1 ' and if not were scored as ' 0 '. Dendrograms were constructed by using Uweighted Pair Group Method of Arithmetic Means (UPGMA) algorithm (Sneath and Sokal, 1973) provided in the software (Statistica computer package 2006, STA_CLU).

\section{RESULTS AND DISCUSSIONS}

Reaction of inoculated fungus for red rot disease on four varieties and their somaclones are shown in table 3. Four varieties namely Isd 37, Isd 38, Isd 39, Isd 40 and their 20 somaclones were inoculated for red rot disease. As a result, Isd 37 variety (source/parent) was found to be resistant (R) while its somaclones CC-37-12 and $\mathrm{CC}-37-86$ also showed resistant $(\mathrm{R})$ reaction. Besides, somaclones of source variety (parent) Isd 37 were obtained as moderately resistant (MR) reaction. Furthermore, somaclones of Isd 38 variety viz. CC-38-2 as moderately resistant (MR), CC-38-10 as moderately susceptible (MS) and also CC-11(38)-8 as susceptible (S) reaction were recorded respectively, while Isd 38 variety showed resistant reaction. On the other hand, Isd 39 and Isd 40 source varieties (parents) with their somaclones were found as resistant reaction against red rot pathogen (Table 3). Some somaclones showed different reaction from their source varieties (parents) for example moderately resistant (MR) somaclones were obtained from resistant (R) source variety Isd 37 (parent) while somaclones CC-38-2 as moderately resistant (MR), CC-38-10 as moderately susceptible (MS) and somaclone CC-38-8 as susceptible $(\mathrm{S})$ were obtained from resistant $(\mathrm{R})$ source variety Isd 38 (parent) against red rot pathogens respectively. Besides, some somaclones showed similar reaction from their resistant source varieties (parents) Isd 37, Isd 39 and also Isd 40. It revealed that in case of reaction against red rot pathogen, induced somaclones showed variation with their source varieties. Similar finding was observed by Ali et al., 2007; Singh et al., 2008 and Jayashree et al., 2010. Red rot infected plant and stem after two months of inoculated by red rot causing virus are shown in the plates 1 .

\section{Dendrogram for resistant and moderately resistant genotypes based on RAPD}

Genetic relationship among the 2 red rot resistant sugarcane varieties and their somaclones (red rot resistant and moderately resistant) produced some different cluster at the linkage distance range from 21 to around 35. Dendrogram based on linkage distance using Unweighted Pair Group Method of Arithmetic Means (UPGMA) indicated segregation of the two red rot resistant sugarcane verities and their somaclones into two main clusters $\mathrm{C}_{1}$ (Isd 39 red rot resistant) and $\mathrm{C}_{2}$ at linkage 
distance of 35 (Figure 1). Cluster $\mathrm{C}_{2}$ produced sub-cluster $\mathrm{SC}_{1}(\mathrm{CC}-39-5$ red rot resistant) and $\mathrm{SC}_{2}$ at the linkage distance 24.5. On the other hand, Sub-cluster $\mathrm{SC}_{2}$ produced sub-cluster $\mathrm{SC}_{3}$ (CC-38-2 moderately resistant) and $\mathrm{SC}_{4}$ (Isd 38 resistant) at the linkage distance of 21 .

\section{Dendrogram for resistant and moderately resistant genotypes based on SSR}

Genetic relationship among the 2 red rot resistant sugarcane varieties and their somaclones (red rot resistant and moderately resistant) produced some different cluster at the linkage distance range from 9.0 to 12.3. Dendrogram based on linkage distance using Unweighted Pair Group Method of Arithmetic Means (UPGMA) indicated segregation of the two red rot resistant sugarcane verities and their somaclones into two main clusters $\mathrm{C}_{1}$ (Isd 38 red rot resistant) and $\mathrm{C}_{2}$ at linkage distance of 12.3 (Figure 2). Cluster $\mathrm{C}_{2}$ produced sub-cluster $\mathrm{SC}_{1}$ (CC-38-2 moderately resistant) and $\mathrm{SC}_{2}$ at the linkage distance 11.5. On the other hand, $\mathrm{Sub}-$ cluster $\mathrm{SC}_{2}$ produced sub-cluster $\mathrm{SC}_{3}$ (Isd 39 resistant) and $\mathrm{SC}_{4}(\mathrm{CC}-39-5$ resistant) at the linkage distance of 9 . Besides, somaclones and their parents showed different types of fingerprinting in case of RAPD and SSR markers. Actually the result indicates that the genetic variability did occur in all the phytohormone treatments and also showed genetic variability. This similar result was reported by Khan et al. (2009).

\section{CONCLUSION}

Some somaclones showed similar reaction from their resistant source varieties Isd 37, Isd 39 and also Isd 40. Besides, it is possible to get variation using tissue culture technique containing 2, 4-D with MS media. It revealed that in case of reaction against red rot pathogen, induced somaclones showed variation with their source varieties. Cluster and sub cluster formation using results of RAPD and SSR markers verified the presence of variability in the red rot resistance somaclones with respect to the parent.

\section{REFERENCES}

Ali, A., Naz, S., Siddiqui, F. A. and Iqbal, J. 2008. Rapid clonal multiplication of sugarcane (Saccharum officinarum) through callogenesis and organogenesis. Pakistan Journal Botany, 40(1): 123-138

Aljanabi, S. M., Forget, L. and Dookun, A. 1999. An improved rapid protocol for the isolation of polysaccharide and polyphenol-free sugarcane DNA. Plant Molecular Biology Reporter, 17: 1-8

Aitken, K. S., Jackson, P. A. and Mclntyre, C. L. 2005. A combination of AFLP and SSR markers provides extensive map coverage and identification of homo(eo)logous linkage groups in a sugarcane cultivar. Theoretical and Applied Genetics, 110: 789-801 
Butterfield, M. K., D'Hont, A. and Berding, N. 2001. The sugarcane genome: a synthesis of current understanding and lessons for breeding and biotechnology. Proceeding of South African Sugarcane Technology Association, 75: 1-5

Hossain, M. A., Shaik, M. M., Shahnawaz, R. M. S., Islam, N. and Miah, M. A. S. 2006. Quality DNA isolation using different methods of sugarcane (Saccharum officinarum L.). Bangladesh Journal of Sugarcane, 28: 65-69

Jayashree, J., Selvi, A. and Nair, N. V. 2010. Characterization of resistance gene analog polymorphisms in sugarcane cultivars with varying levels of red rot resistance. Electronic Journal Plant Breeding, 1(4): 1191-1199

Kochhar, S. L. 1998. Economic Botany in the tropics. Second Edition Macmillan. India Ltd., pp. $1-476$

Khan, I. A., Dahot, M. U., Seema, N., Yasmin, S., Bibi, S., Raza, G., Khatri, A. and Naqvi, M. H. 2009. Direct regeneration of sugarcane plantlets: A tool to unravel genetic heterogeneity. Pakistan Journal of Botany, 41(2): 797-814

Lakshmanan, P., Geijskes, R. J., Wang, L., Elliott, A., Grof, C. P. L., Berding, N. and Smith, G. R. 2006. Development and hormonal regulation of direct shoot organogenesis and somatic embryogenesis in sugarcane (Saccharum spp. Interspecific hybrids) leaf culture. Plant Cell Reports, 25: 1007-1015

Mondal, S., Sutar, S. R. and Badigannavar, A. M. 2009. Assesssment of genetic diversity in cultivated groundnut (Arachis hypogaea $\mathrm{L}$ ) with differential responses to rust and late spot using ISSR markers. Journal of Genetics and Plant Breeding, 63(3): 219-224

Shahnawaz, R. M. S. 2006. DNA isolation, quantification and fingerprinting using RAPD markers of sugarcane (Saccharum officinarum L.). A thesis of Master's of Science (M. Sc) in Biotechnology and Genetic Engineering Dept., Islamic University, Kushtia, Bangladesh

Singh, G., Sandhu, S. K., Meeta, M., Singh, K., Gill, R. and Gosal, S. S. 2008. In vitro induction and characterization of somaclonal variation for red rot and other agronomic traits in sugarcane. Euphytica, 160(1): 35-47

Sneah, P. H. A. and Sokal, R. R. 1973. Numerical taxonomy. W.H., Freeman and Co., San Francisco, CA. pp. 21-28

Viswanathan, R. and Samiyappan, R. 2002. Induced systemic resistance by fluorescent pseudomonads against red rot disease of sugarcane caused by Colletotrichum falcatum. Crop Protection, 21: 1-10

Williams, J. G. K., Kubelik, A. R., Livak, K. J., Rafalski, J. A. and Tingey, S. V. 1990. DNA polymorphisms amplified by arbitrary primers are useful as genetic markers. Nucleic Acids Research, 18: 6531-6535 
Table 1. Criteria for determination of diseases index for screening sugarcane somaclones and their sources varieties

\begin{tabular}{lll|}
\hline S1. No. & Criteria/Characters & Numerical rating/score \\
\hline 1 & Lesions width above the inoculated internode $(0-3)$ & \\
a) Vary rare lesion or no lesion developed & 0 \\
b) Rare lesion $\left(1 / 3^{\text {rd }}\right.$ or less spread full width) & 1 \\
c) Medium lesion (1/3 ${ }^{\text {rd }}$ to $2 / 3^{\text {rd }}$ spread of full width) & 2 \\
d) High lesion (covered the full width) & 3 \\
Nodal transgression $(0-3)$ & \\
a) Lesion restricted in the inoculated internode & 0 \\
b) One node crossed & 1 \\
c) Two nodes crossed & 2 \\
d) Tree or more nodes crossed & 3 \\
Presence of white patches $(0-2)$ & \\
a) White patch absent & 0 \\
b) White patch restricted & 1 \\
c) white patch progressive & 2 \\
Condition of top (0-1) & \\
a) Green & 0 \\
b) Yellow/dry &
\end{tabular}

Table 2. Disease index of Red rot

\begin{tabular}{cc}
\hline Disease Index & Disease reaction \\
\hline $0-2.0$ & $\mathrm{R}$ \\
$2.1-4.0$ & $\mathrm{MR}$ \\
$4.1-6.0$ & $\mathrm{MS}$ \\
$6.1-8.0$ & $\mathrm{~S}$ \\
$8.1-$ above & $\mathrm{HS}$ \\
\hline
\end{tabular}

Note: $\quad \mathrm{R}=$ Resistant, $\mathrm{MR}=$ Moderately Resistant, $\mathrm{MS}=$ Moderately Susceptible $\mathrm{S}=$ Susceptible and HS= Highly Susceptible 
Table 3. Effects of inoculated fungus for red rot disease on sugarcane somaclones and their source varieties (parents)

\begin{tabular}{|c|c|c|}
\hline Sl. No. & Variety/Somaclones & Reaction \\
\hline \multicolumn{2}{|c|}{ 1. Standard Variety Isd 37} & Resistant (R) \\
\hline 2. & $\mathrm{CC}-37-10$ & Moderately Resistant (MR) \\
\hline 3. & $\mathrm{CC}-37-12$ & Resistant (R) \\
\hline 4. & $\mathrm{CC}-37-28$ & Moderately Resistant (MR) \\
\hline 5. & $\mathrm{CC}-37-51$ & Moderately Resistant (MR) \\
\hline 6. & $\mathrm{CC}-37-65$ & Moderately Resistant (MR) \\
\hline 7. & CC-37-74 & Moderately Resistant (MR) \\
\hline 8. & CC-37-81 & Moderately Resistant (MR) \\
\hline 9. & $\mathrm{CC}-37-83$ & Moderately Resistant (MR) \\
\hline 10. & $\mathrm{CC}-37-86$ & Resistant (R) \\
\hline \multicolumn{2}{|c|}{ 11. Standard Variety Isd 38} & Resistant (R) \\
\hline 12. & $\mathrm{CC}-38-2$ & Moderately Resistant (MR) \\
\hline 13. & $\mathrm{CC}-38-8$ & Susceptible (S) \\
\hline 14. & $\mathrm{CC}-38-10$ & Moderately Susceptible (MS) \\
\hline \multicolumn{2}{|c|}{ 15. Standard Variety Isd 39} & Resistant (R) \\
\hline 16. & CC-39-1 & Resistant (R) \\
\hline 17. & $\mathrm{CC}-39-5$ & Resistant (R) \\
\hline 18. & CC-39-7 & Resistant (R) \\
\hline 19. & $\mathrm{CC}-39-12$ & Resistant (R) \\
\hline 20. & $\mathrm{CC}-39-25$ & Resistant (R) \\
\hline 21. & $\mathrm{CC}-39-26$ & Resistant (R) \\
\hline \multicolumn{2}{|c|}{ 22. Standard Variety Isd 40} & Resistant (R) \\
\hline 23. & $\mathrm{CC}-40-7$ & Resistant (R) \\
\hline 24. & $\mathrm{CC}-40-8$ & Resistant (R) \\
\hline
\end{tabular}



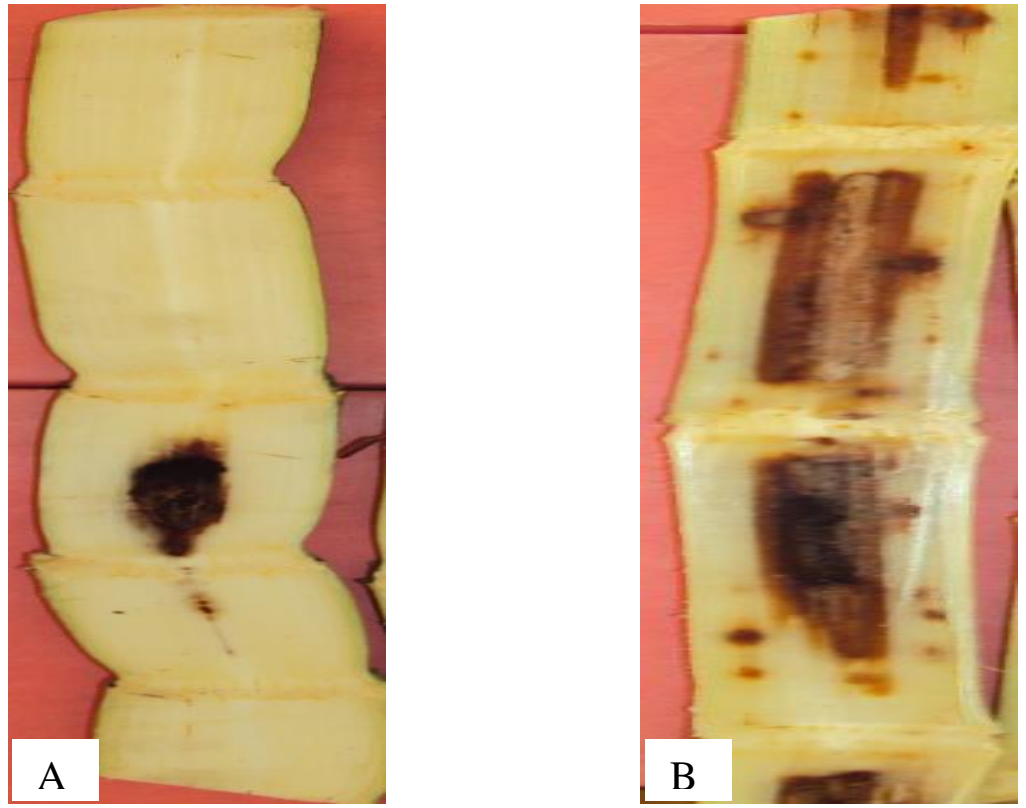

Plate 1. Somaclones showing A) Red rot resistance and B) Red rot susceptibility

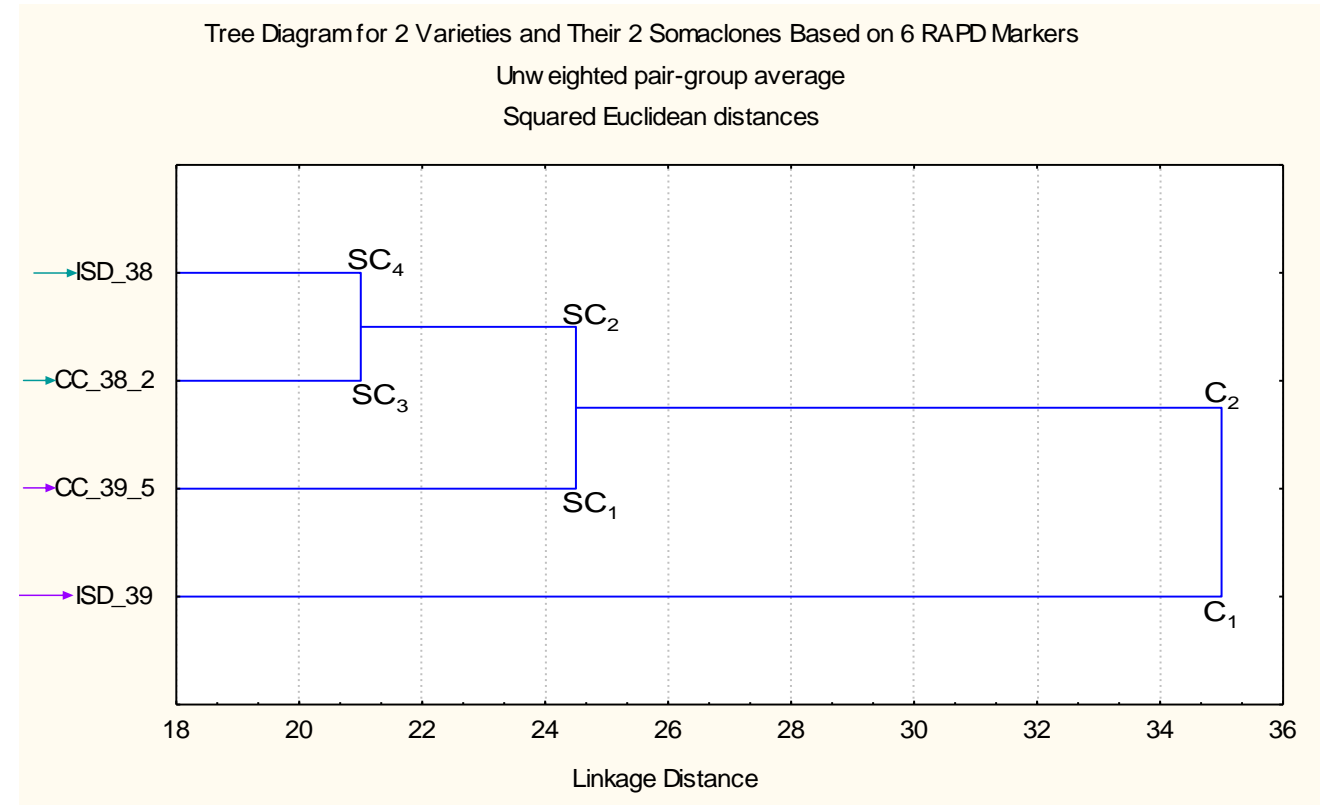

Figure 1. Cluster analysis by Unweighted Pair Group Method of Arithmetic means (UPGMA) of 2 sugarcane varieties and their 2 somaclones based on 6 RAPD 
Tree Diagram for 2 Varieties and Their 2 Somaclones Based on 9 SSR Markers Unw eighted pair-group average

Squared Euclidean distances

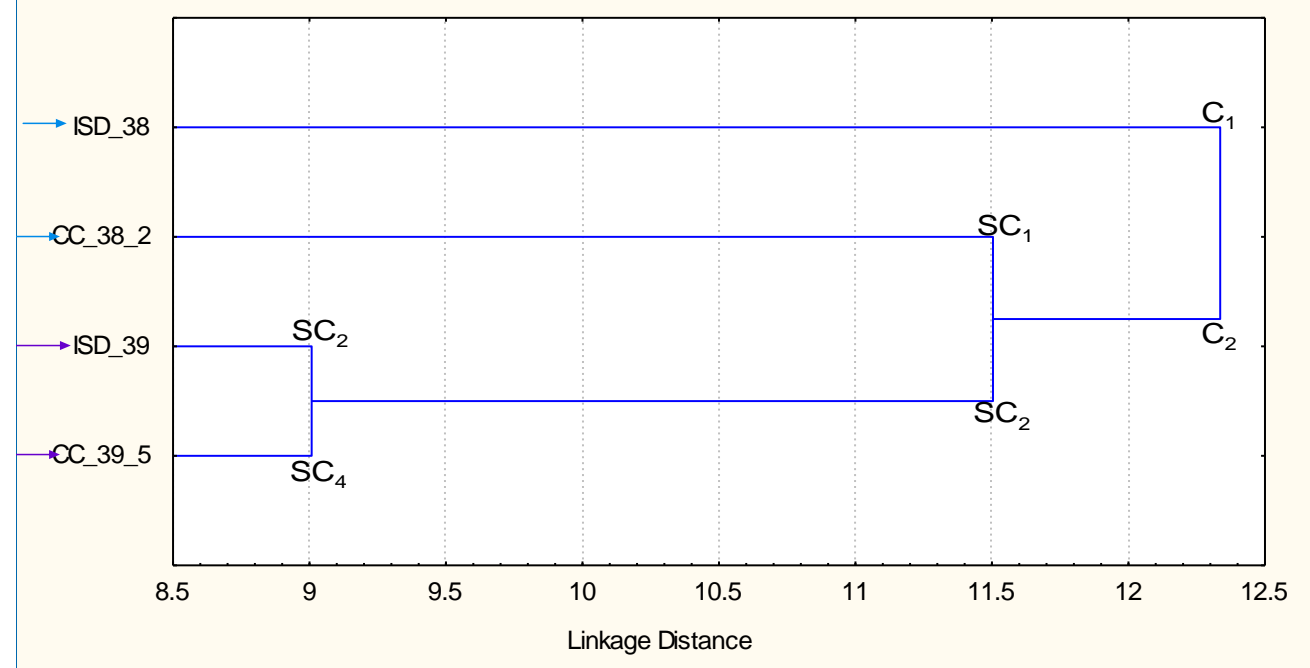

Figure 2. Cluster analysis by Unweighted Pair Group Method of Arithmetic means(UPGMA) of 2 sugarcane varieties and their 2 somaclones based on microsatellite (SSR) markers 